\title{
REGULACIÓN DE LA MEDIACIÓN FAMILIAR EN ESPAÑA ESTADO DE LA CUESTIÓN A LA LUZ DEL PROYECTO DE LEY DE MEDIACIÓN REFLEXIONES SOBRE LAS POSIBILIDADES DE MEDIAR Y SUS LÍMITES
}

\author{
Cristina MERINO ORTIZ
}

Abogada y mediadora del Servicio Público de Mediación Familiar del Gobierno Vasco

Juan MORCILLO JIMÉNEZ

ABOGADO Y MEDIADOR DE ATYMEPAS

SUMARIO: I. Introducción. Marco en el que se desarrolla la mediación familiar. II. Referencias legislativas españolas sobre la mediación familiar. Posibilidades y límites. II.I. Referencias constitucionales como marco de desarrollo de la mediación. II.2. Ley de Enjuiciamiento Civil I/2000, de 7 de enero y Ley I5/2005 de 8 de julio, por la que se modifica la Ley de Enjuiciamiento civil y el Código civil en materia de separación y divorcio. II.3. Referencias legislativas civiles que favorecen el desarrollo de la mediación ante la diversidad de conflictos familiares. II.4. Ley Orgánica I/2004, de 28 de diciembre, de Medidas de Protección Integral contra la Violencia de Género. III. Proyecto de ley de mediación en asuntos civiles y mercantiles. III.I. Concepto de mediación. III.2. Voluntariedad, tutela judicial efectiva y principio dispositivo en su vertiente sustantiva y adjetiva. III.3. Principio de neutralidad. III.4. Finalización del proceso. El acuerdo y su ejecutividad. III.5. Formación de la persona mediadora. IV. Regulación autonómica en mediación familiar. Principios reguladores y límite. V. Conclusiones. Aspectos comunes sobre la viabilidad de la mediación y cuestionamientos éticos. VI. Bibliografía.

RESUMEN: Este artículo describe la implantación de la mediación como forma de resolución y gestión de conflictos en España en ausencia de normas sobre la materia. Se analiza toda la regulación que propició su desarrollo, hasta llegar a las leyes autonómicas sobre mediación y al proyecto de ley de mediación civil y mercantil. Mención especial se presta al estudio de los principios inspiradores de las normas de mediación, que favorecen la reflexión sobre las posibilidades y límites de los procesos de mediación y su ética.

Palabras ClaVE: Mediación, regulación, principios, límites y ética.

REGULATION OF FAMILY MEDIATION IN SPAIN. THE STATE OF THE QUESTION IN THE LIGHT OF THE DRAFT LAW MEDIATION. REFLECTIONS ON THE POSSIBILITIES OF MEDIA AND THEIR LIMITS.

ABSTRACT: This article makes a brief reference to the introduction of mediation as a means of conflict resolution in Spain in the absence of relevant rules. It discusses and analyzes the regulation that led to its development, reaching regional laws on mediation and the bill of civil and commercial mediation. It is a study of the principles contained in the rules of mediation and reflects on the possibilities and limits of mediation and ethics.

KEYwORDS: Mediation, legal regulation, principles, limits and ethics. 


\section{Introducción. Marco en el que se desarrolla la mediación familiar}

La mediación, representando uno de los sistemas no adversariales de resolución de conflictos, es conocida en la jerga científica por sus siglas ADR (Alternative Dispute Resolution $)^{\mathrm{I}}$. Se define como una forma útil de abordar las diversas controversias que surgen en la interpretación y aplicación de los negocios jurídicos de derecho de familia e instituciones familiares (matrimonio, filiación, adopción, derecho de alimentos...)

El objetivo que se pretende con este artículo es la identificación del marco normativo en el que se sitúa actualmente la mediación desde un prisma práctico, es decir, únicamente para los aspectos que son de aplicación en la intervención directa en mediación, bien por las oportunidades que ofrece, bien por los límites que impone. Con tal finalidad, se ha partido de la tesis doctoral de Merino (20II) en lo referente a la regulación normativa en el ámbito europeo, estatal y autonómico, que profundiza en el análisis de lo que puede implicar dicho marco normativo. En la línea de investigación de dicho estudio, se han tenido en cuenta las referencias a los principios de neutralidad, imparcialidad, desequilibrio de poder, así como a los límites de la intervención que se reflejan en las características de inmediatez y ausencia de violencia.

Con el interés de conocer el marco legislativo que permita entender el desarrollo de esta materia, se comienza con las Recomendaciones y Directivas del Consejo de Europa y de la Unión Europea en la medida que son de aplicación a los Estados miembros, con especial atención a sus principios, fundamentalmente enumerados y dotados de contenido en la Recomendación (98)I, del Comité de Ministros a los Estados Miembros del Consejo de Europa sobre la Mediación Familiar. A continuación se centra el estudio en España, partiendo del reconocimiento que otorga la Constitución Española a una serie de derechos fundamentales que son los que permiten que la mediación sea un proceso aceptado y promovido, también, desde el Derecho español. Se procede, posteriormente, a la identificación de las posibilidades que reconoce el Derecho Civil en lo concerniente a los conflictos familiares, tanto en lo relativo a la ruptura de pareja como a aspectos derivados de las propias relaciones familiares (relación de abuelos/abuelas con nietos y nietas; relación de dependencia). Una vez consideradas las posibilidades de mediación, se da paso a reconocer sus límites, principalmente asociados a la violencia de género, para lo cual se hace una síntesis del discurso que esta ley de protección integral contra la violencia refleja.

En lo referente al ámbito español, se analiza el proyecto de ley de mediación familiar que traspone al derecho español la Directiva 2008/52/CE del Parlamento Europeo y del Consejo, de 2i de mayo de 2008, sobre ciertos aspectos de la mediación en asuntos civiles y mercantiles ${ }^{2}$. En dicha norma se condensan los esfuerzos de la Comisión Europea, iniciados en el año $2002^{3}$ para dotar al espacio común europeo de seguridad y justicia de formas alternativas de resolución de conflictos. Esta directiva pone de manifiesto cómo la mediación se articula como un complemento adecuado a la solución judicial de contiendas,

\footnotetext{
${ }^{\text {I }}$ En el seno del Consejo de Europa, se ha producido una interesante continuidad en la petición de una mayor aplicación de estas soluciones alternativas, tal como resulta de las siguientes recomendaciones del Comité de Ministros dirigidas a los Estados miembros: Recomendación $\mathrm{n}^{\circ} \mathrm{R}(86)$ I2 relativa a las medidas para prevenir y reducir la excesiva carga de trabajo de los tribunales; Recomendación $n^{\circ} \mathrm{R}\left(\mathrm{9}^{8}\right)$ I sobre la mediación familiar; Recomendación $n^{\circ} \mathrm{R}$ (99) I9 sobre la mediación en cuestiones penales; Recomendación $n^{\circ}$ Rec (200I) 9 sobre alternativas a los litigios entre autoridades administrativas y particulares; Recomendación $n^{\circ}$ Rec (2002) Io sobre la mediación en cuestiones civiles; el Dictamen $n^{\circ} 6$ (2004), de 20 de abril de 2005, del Consejo Consultivo de los Jueces Europeos (CCJE) dirigido al Comité de Ministros del Consejo de Europa sobre un proceso justo en un tiempo razonable y la función del juez en los litigios teniendo en cuenta los medios alternativos de resolución de disputas; y los trabajos desarrollados en febrero de 2008 por la Comisión Europea para la Eficiencia de la Justicia (CEPEJ), CM (2008) 23.

${ }^{2}$ DOUE n ${ }^{\circ} \mathrm{i} 36$, de 24 de mayo de 2008 , p. 3.

${ }^{3}$ Comisión Europea, Libro verde sobre las modalidades alternativas de solución de conflictos en el ámbito del derecho civil y mercantil, COM (2002) I96 final, Bruselas, I9 de abril de 2002, pp. 6-7.
} 
lo que en palabras de la propia Directiva se traduce en «una relación equilibrada entre la mediación y el proceso judicial». Esa era la idea de la Comisión Europea al proponer al Parlamento y Consejo la adopción de la Directiva: «el concepto de acceso a la justicia debe incluir la promoción del acceso a procedimientos adecuados de resolución de litigios para particulares y empresas, y no solamente el acceso al sistema judicial» ${ }^{4}$.

Desde el momento en que la mediación es considerada por el Consejo General del Poder Judicial (mención especial requiere el proyecto piloto de mediación intrajudicial en el ámbito familiar y penal de 2006) como un procedimiento de interés para lograr sus objetivos de modernización y agilización de la justicia, es conveniente conocer cuáles son las posibilidades que ofrece este marco normativo, así como sus limitaciones, ya que de éste modo resultarán de mayor impacto los estudios e investigaciones que se realicen en esta materia.

\section{Referencias legislativas españolas sobre la mediación familiar: Posibilidades y} límites

II.I. Referencias constitucionales como marco de desarrollo de la mediación

La mediación familiar viene siendo un instrumento de solución de conflictos ampliamente utilizado y regulado tanto en países de nuestro entorno como en diversas comunidades autónomas españolas. La posibilidad de pactar separaciones y divorcios de mutuo acuerdo, como consecuencia de la aprobación de la Ley de Divorcio de i981 favoreció que en la década de los 90 se abrieran los primeros centros de profesionales en mediación (Bernal, I994) y servicios específicos de mediación públicos y privados. En este contexto destaca la labor que los equipos técnicos de los juzgados de familia comenzaron en la década de los ochenta y su extensión a diferentes experiencias que se fueron llevando a cabo en Barcelona ${ }^{5}$, Madrid ${ }^{6}$, San Sebastián, Ibiza, Sevilla, Oviedo y Bilbao (Merino, 20ıo).

Si bien, en la actualidad, no existe una regulación nacional que dote a la mediación de un marco jurídico propio, debemos tener en cuenta diversas referencias que ofrecen un campo al desarrollo de la mediación y a la regulación de la misma por las Comunidades Autónomas. Para que la mediación haya tenido su encaje en el Ordenamiento jurídico español han sido necesarios cambios sociales y legislativos que se sitúan en las últimas décadas, siendo la Constitución de I978 el marco de referencia y presupuesto necesario para dar contenido a la mediación.

Consideramos que se debe de partir de los principios constitucionales de libertad individual y autonomía de la persona para regular sus propios intereses (vid. Art. I.I CE que proclama la libertad como uno de los valores superiores del ordenamiento jurídico); artículo IO.I CE, que se refiere a la dignidad de la persona y al libre desarrollo de la personalidad como fundamentos del orden político; artículo I4 CE en cuanto al reconocimiento de la igualdad de mujeres y hombres, cuestión fundamental para empezar a hablar de la mediación en conflictos familiares; artículo I6 CE en la medida que reconoce el derecho a

\footnotetext{
${ }^{4}$ Comisión Europea, Propuesta de Directiva del Parlamento Europeo y del Consejo sobre ciertos aspectos de la mediación en asuntos civiles y mercantiles, Bruselas, 22 de octubre de 2004, COM (2004) 7I8 final, apartado I.I.I., p. 2.

${ }^{5}$ Ortuño, P. participó durante 7 años en el desarrollo de un proyecto de mediación vinculado a los juzgados, que ha generado un grupo de profesionales que han contribuido a prestigiar esta alternativa a la resolución judicial de los conflictos y que constituyó la Asociación Catalana para el desarrollo de la Mediación (ACMA).

${ }^{6}$ En Septiembre de I990, el Ministerio de Asuntos Sociales, desde la Dirección General de Protección Jurídica del Menor, aprueba el primer programa de Mediación Familiar. En febrero de I99I, se pone en marcha un programa piloto en el Centro de Psicología de Apside, en Madrid.
} 
la libertad ideológica, siendo la base de cualquier conflicto la diversidad de valores, es requisito fundamental el respeto a los mismos; en el artículo i8 se reconoce el derecho fundamental a la intimidad familiar, que implica la defensa de la privacidad familiar, delegando en medidas indirectas la protección familiar, especialmente de las personas incapacitadas y menores; los artículos 33 y $38 \mathrm{CE}$, en los que se garantiza el derecho de propiedad privada y la libertad de empresa, con las consecuencias inherentes a ambos conforme a la regulación legal de los mismos. No podemos dejar de referirnos al artículo 39 $\mathrm{CE}$, en virtud del cual los poderes públicos deben asegurar la protección de la familia, así como la protección integral de los hijos e hijas.

En definitiva, la familia es considerada el núcleo fundamental de la sociedad y, por tanto, requiere una protección específica. En la medida que las relaciones familiares son consideradas medios para el desarrollo de la personalidad individual, el Derecho garantiza el orden público en materia de familia y autonomía de la voluntad.

II.2. Ley de Enjuiciamiento Civil I/2000, de 7 de enero y Ley I5/2005 de 8 de julio, por la que se modifica la Ley de Enjuiciamiento civil y el Código civil en materia de separación y divorcio

El Derecho Civil, como derecho privado por excelencia, tiene como eje a la persona y su autonomía en sus distintas manifestaciones. Este aspecto coincide con la esencia de la mediación y demás procesos de gestión de conflictos, en los que son las personas las protagonistas directas de su proceso y responsables de sus acuerdos. Por ello, no sería erróneo afirmar que la nota característica sin la cual no se podría entender la mediación familiar es la tendencia a la privatización del derecho de familia y, sin lugar a dudas, esta privatización tuvo su punto de partida con la Ley 30/I98I, de 7 de julio, al menos en lo que se refiere a los procesos de separación y divorcio conocidos como «de mutuo acuerdo», al otorgar a los cónyuges la facultad de solicitar la separación y el divorcio una vez cumplidos los requisitos que establecían los artículos 8I.I y 86 del Código Civil7 con la obligación de

\footnotetext{
7 Decía el Artículo 8I, se decretará judicialmente la separación, cualquiera que sea la forma de celebración del matrimonio:

1. A petición de ambos cónyuges o de uno con el consentimiento del otro, una vez transcurrido el primer año del matrimonio. Deberá necesariamente acompañarse a la demanda la propuesta del convenio regulador de la separación conforme a los artículos 90 y 103 de este Código.

Y el Artículo 86, son causas de divorcio:

1. El cese efectivo de la convivencia conyugal durante, al menos, un año ininterrumpido desde la interposición de la demanda de separación formulada por ambos cónyuges o por uno de ellos con el consentimiento del otro, cuando aquélla se hubiera interpuesto una vez transcurrido un año desde la celebración del matrimonio.

2. El cese efectivo de la convivencia conyugal durante, al menos. un año ininterrumpido desde la interposición de la demanda de separación personal, a petición del demandante o de quien hubiere formulado reconvención conforme a lo establecido en el artículo 82, una vez firme la resolución estimatoria de la demanda de separación o, si transcurrido el expresado plazo, no hubiera recaído resolución en la primera instancia.

3. El cese efectivo de la convivencia conyugal durante, al menos, dos años ininterrumpidos:

a. Desde que se consienta libremente por ambos cónyuges la separación de hecho o desde la firmeza de la resolución judicial. o desde la declaración de ausencia legal de alguno de los cónyuges, a petición de cualquiera de ellos.
}

b. Cuando quien pide el divorcio acredite que, al iniciarse la separación de hecho, el otro estaba incurso en causa de separación. 
acompañar a la demanda de separación o divorcio una propuesta de convenio regulador. Por ello, de modo indirecto y en aquel entonces sin utilizar el término mediación, la ley propició que diversas parejas se acercaran a la forma de trabajo de la mediación para negociar los acuerdos que luego se trasladarían al Convenio Regulador por sus respectivos letrados y letradas. Asimismo, otro precedente de la mediación familiar lo podemos encontrar en el Derecho Aragonés en la Junta de parientes, tal como ha investigado De Sala (2003).

Esta brecha abierta a la privatización no tuvo otro refuerzo hasta que se promulgó la Ley de Enjuiciamiento Civil I/2000, de 7 de enero, que confirmando el principio de autonomía de la voluntad de las partes en materia de derecho de familia, impulsa la conveniencia de los mutuos acuerdos, facilitando la conversión de los procesos contenciosos en consensuados, en todo o en parte de las medidas a acordar, regulándolo expresamente, tanto para las medidas definitivas (art. 774.I LEC) como para las de carácter provisional (arts. 77I.3 y 773.I LEC) ${ }^{8}$.

Por último, hasta el momento actual, el mayor fortalecimiento de la autonomía de la voluntad en el ámbito del derecho de familia vendrá con la Ley I5/2005 de 8 de julio, por la que se modifican el Código Civil y la Ley de Enjuiciamiento Civil en materia de separación y divorcio, que parte de la libertad como valor superior de nuestro ordenamiento jurídico proclamando que el mismo ha de tener su adecuado reflejo en el matrimonio, apostando claramente por fortalecer la autonomía de la voluntad de los cónyuges que será determinante, tanto en la continuación del vínculo matrimonial, como en su extinción. Fruto de este gran impulso se deja sin contenido los artículos 82 y 87 del Código Civil pasándose de un sistema de separación y divorcio causales a otro en que se admiten la separación y el divorcio no sólo por mutuo disenso de los cónyuges, (art. 8I.I Cc) sino también por la voluntad de cualquiera de ellos (art. 82.2 Cc). Basta, por tanto, la voluntad unilateral de uno de los cónyuges, transcurrido el plazo de tres meses de vigencia del matrimonio, para que se declare la separación o el divorcio, sin que el otro cónyuge pueda formular oposición alguna, ni el juez pueda denegar la solicitud salvo por motivos procesales. Excepcionalmente, será necesaria la alegación y prueba de causa, cuando la petición se formule durante el indicado plazo de tres meses (Art. 8I.2 ${ }^{\circ}$ del Código Civil). Igualmente novedosa es la incorporación del concepto de custodia compartida ${ }^{9}$ que hace la Ley.

4. El cese efectivo de la convivencia conyugal durante el transcurso de, al menos, cinco años, a petición de cualquiera de los cónyuges.

5. La condena en sentencia firme por atentar contra la vida del cónyuge, sus ascendientes o descendientes.

6. Cuando el divorcio sea solicitado por ambos o por uno con el consentimiento del otro, deberá necesariamente acompañarse a la demanda o al escrito inicial la propuesta convenio regulador de sus efectos, conforme a los artículos 90 Y 103 de este Código.

8 Art. 774.I LEC «En la vista del juicio, si no lo hubieren hecho antes, conforme a lo dispuesto en los artículos anteriores, los cónyuges podrán someter al tribunal los acuerdos a los que hubieren llegado para regular las consecuencias de la nulidad, separación o divorcio y proponer la prueba que consideren conveniente para justificar su procedencia».

Art. 77I.3 LEC «En el acto de la comparecencia a que se refiere el apartado anterior, si no hubiere acuerdo de los cónyuges sobre las medidas a adoptar...»

Art. 773.I LEC «...También podrán ambos cónyuges someter a la aprobación del tribunal el acuerdo al que hubieren llegado sobre tales cuestiones...».

9 Se pretende reforzar con esta ley la libertad de decisión de padres y madres respecto del ejercicio de la patria potestad. En este sentido, se prevé expresamente que puedan acordar en el convenio regulador que el ejercicio se atribuya exclusivamente a uno de ellos, o bien a ambos de forma compartida. 
En esta misma Ley encontramos la primera referencia expresa a la mediación, definida en su Exposición de Motivos $^{\mathrm{IO}}$ como: «un recurso voluntario para dirimir los litigios familiares que se incardina dentro del procedimiento de mutuo acuerdo y que es distinto al modo en que tradicionalmente se llegaba al procedimiento consensuado ${ }^{\mathrm{II}} \gg$. Asimismo, la Disposición Final Tercera de la Ley establece los principios mínimos (voluntariedad, imparcialidad, neutralidad y confidencialidad) en los que se debe de asentar la futura Ley de Mediación ${ }^{12}$. Estas referencias a la mediación como solución alternativa al proceso judicial contencioso no venían recogidas en el Proyecto de Ley que el Gobierno (PSOE) remite a las Cortes, fue en la fase de enmiendas de su tramitación parlamentaria en el Congreso y Senado en la que se suscita éste interés, estando todos los grupos parlamentarios interesados en dar cumplimiento a las recomendaciones del Consejo de Ministros de la UE y regular en España la mediación familiar. Citamos por su interesante contenido la enmienda propuesta por el grupo parlamentario Izquierda Verde-Izquierda Unidad- Iniciativa per Catalunya Verds ${ }^{13}$, de la que destacamos la referencia que hace sobre la derivación al proceso de mediación que pueden realizar los jueces, al principio de voluntariedad, y a la prohibición de iniciar un procedimiento de mediación en situaciones de violencia doméstica.

Finalmente, y pese a alabar todos los grupos parlamentarios los beneficios que puede conllevar la mediación en la solución de conflictos familiares, el texto definitivo tras reconocer las ventajas de la mediación ${ }^{\mathrm{I} 4}$ quedó limitado a permitir suspender el proceso para acudir a mediación ${ }^{\mathrm{I5}} \mathrm{y}$ a poder presentar en el proceso los acuerdos de mediación ${ }^{\mathrm{I} 6}$, estableciendo un acuerdo de intenciones para una futura ley de mediación donde se recojan unos principios y el respeto a los servicios de mediación creados por las Comunidades

1o Dice la Exposición de Motivos de la LEY 15/2005, de 8 de julio, por la que se modifican el Código Civil y la Ley de Enjuiciamiento Civil en materia de separación $y$ divorcio. «Con el fin de reducir las consecuencias derivadas de una separación y divorcio para todos los miembros de la familia, mantener la comunicación y el diálogo, y en especial garantizar la protección del interés superior del menor».

II «Se establece la mediación como un recurso voluntario alternativo de solución de los litigios familiares por vía de mutuo acuerdo con la intervención de un mediador, imparcial y neutral».

${ }^{12}$ Disposición Final Tercera de la Ley 15/2005, de 8 de julio «El Gobierno remitirá a las Cortes un proyecto de ley sobre mediación basada en los principios establecidos en las disposiciones de la Unión Europea, y en todo caso en los de voluntariedad, imparcialidad, neutralidad y confidencialidad y en el respeto a los servicios de mediación creados por las Comunidades Autónomas».

${ }^{13}$ En concreto se trató de la Enmienda 43 de Izquierda Verde -Izquierda Unida- Iniciativa per Catalunya Verds, sobre adición de un articulo XXX: «Los cónyuges podrán acordar acudir a la mediación familiar antes del inicio del proceso judicial o durante el desarrollo del mismo, previa comunicación al juez y suspensión del procedimiento, en este último supuesto. Si dadas las circunstancias del caso, la autoridad judicial considera que las diferencias entre los cónyuges pueden ser resueltas mediante acuerdo, podrá remitir a los cónyuges a mediación familiar con la finalidad de que intenten resolver aquellas y que presente una propuesta de convenio regulador, sometido al mismo régimen que el establecido en el artículo 90 de este Código. En todo caso la mediación familiar tendrá que ser aceptada voluntariamente por los cónyuges, sin perjuicio, de su derecho a acceso a los tribunales. No podrá iniciarse un proceso de mediación familiar cuando exista una situación de violencia domestica, ni cualquiera otra circunstancias que impida a las partes mantener una situación de igualdad en la negociación y lograr los acuerdos de una manera libre y voluntaria. Lo que se hubiere dicho o escrito con ocasión de un intento de conciliación, cualquiera que fuera la forma en que hubiera tenido lugar, no podrá ser invocado a favor o en contra de uno de los esposos o de un tercero en al continuación del procedimiento».

${ }^{14}$ Con el fin de reducir las consecuencias derivadas de una separación y divorcio para todos los miembros de la familia, mantener la comunicación y el diálogo, y en especial garantizar la protección del interés superior del menor, se reconoce la mediación como un «recurso voluntario alternativo de solución de los litigios familiares por vía de mutuo acuerdo con la intervención de un mediador, imparcial y neutral».

${ }^{15}$ En su Disposición final primera se refiere a la modificación de la Ley $1 / 2000$, de 7 de enero, de Enjuiciamiento Civil, que introduce una nueva regla $7^{\mathrm{a}}$ al artículo 770 , que permite a las partes de común acuerdo solicitar la suspensión del proceso y someterse a mediación.

${ }^{16}$ Asimismo, se modifica el apartado 2 del artículo 777, con la inclusión entre los certificados y documentos a aportar, el acuerdo final alcanzado en el procedimiento de mediación familiar. 
Autónomas ${ }^{17}$.

${ }^{17}$ En su Disposición final tercera la Ley establece que: «El Gobierno remitirá a las Cortes un proyecto de ley sobre mediación basada en los principios establecidos en las disposiciones de la Unión Europea, y en todo caso en los de voluntariedad, imparcialidad, neutralidad $y$ confidencialidad $y$ en el respeto a los servicios de mediación creados por las Comunidades Autónomas». 
II.3. Referencias legislativas civiles que favorecen el desarrollo de la mediación ante la diversidad de conflictos familiares

La normativa española ofrece una diversidad de leyes, que sin hacer una referencia expresa a la mediación, regulan una serie de relaciones familiares que en situaciones de conflicto pueden ser abordadas mediante procesos de mediación. Por orden cronológico, se han identificado la ley que regula el derecho de visitas entre abuelos y abuelas con sus respectivas nietas y nietos; la ley que reconoce el derecho a contraer matrimonio entre personas del mismo sexo; la ley que promueve la autonomía y cuidados de personas dependientes; y, por último, la ley de igualdad entre hombres y mujeres.

Ley 42/2003, de 21 de noviembre, de modificación del Código Civil y de la Ley de Enjuiciamiento Civil en materia de relaciones familiares de los nietos con los abuelos.

Esta ley reconoce que son las abuelas y abuelos quienes pueden desempeñar un papel crucial para la estabilidad del menor, en la medida que se mantengan ajenos a las situaciones de ruptura de pareja o matrimonial. En este sentido, la ley les atribuye una autoridad moral y una distancia con respecto a los problemas de la pareja que puede ayudar a nietas y nietos a racionalizar situaciones de conflicto familiar, favoreciendo en este sentido su estabilidad y su desarrollo. Es en estas situaciones donde la mediación encuentra un campo de actuación de gran interés, al ofrecer un espacio en el que gestionar situaciones de hostilidad o enfrentamiento entre padres, madres que se convierten en yernos o nueras, todas estas personas interesadas en el bienestar de esos hijos e hijas y buscando un lugar donde comunicarse, reflexionar y concretar en qué términos se va a desarrollar tal relación. Por tanto, esta ley tiene dos objetivos, siendo ambos compatibles con el espíritu de los procesos de mediación:

- El reconocimiento del derecho de visitas específicamente para la relación entre abuelos, abuelas y nietos y nietas, tanto en caso de ruptura familiar, como en el caso de simple dejación de obligaciones por parte de los progenitores.

- La atribución a estas abuelas y abuelos de un papel relevante en el caso de dejación de las obligaciones derivadas del rol de madre y padre.

Con el ánimo de lograr cualquiera de los dos objetivos, la mediación favorece el espacio y el proceso que minimice los efectos negativos y traumáticos de una situación de crisis de pareja o de dificultad en la relación familiar.

Ley 13/2005, de 1 de julio, por la que se modifica el Código Civil en materia de derecho a contraer matrimonio.

La regulación del matrimonio en el derecho civil contemporáneo ha reflejado los modelos y valores dominantes en las sociedades europeas y occidentales. Teniendo estos códigos su origen en el Código Civil francés de I804, en ese momento no precisaban referirse al matrimonio entre personas del mismo sexo. La sociedad evoluciona y paralelamente los modelos de convivencia se diversifican, siendo la realidad social mucho más rica, plural y dinámica que la sociedad en la que surge el Código Civil español de i889. Es en esta ley I3/2005 en la que se reconoce la convivencia entre personas del mismo sexo, su derecho a contraer matrimonio y, consiguientemente, a interrumpirlo o ponerle fin. Con lo cual, se les atribuye el derecho a acudir a mediación en caso de que se considere un proceso adecuado para la gestión de sus conflictos interpersonales. 
Ley 39/2006, de 14 de diciembre, de Promoción de la autonomía personal y la atención a las personas en situación de dependencia.

En esta norma se presta atención a las personas en situación de dependencia y la promoción de su autonomía personal, constituyendo uno de los principales retos de la política social de los países desarrollados. El reto es, precisamente, atender las necesidades de aquellas personas que, por encontrarse en situación de especial vulnerabilidad, requieren apoyos para desarrollar las actividades esenciales de la vida diaria, alcanzar una mayor autonomía personal y poder ejercer plenamente sus derechos de ciudadanía.

El reconocimiento de los derechos de las personas en situación de dependencia ha sido puesto de relieve por numerosos documentos y decisiones de organizaciones internacionales, como la Organización Mundial de la Salud, el Consejo de Europa y la Unión Europea. Tal como expresa esta ley, la sociedad está viviendo el «envejecimiento del envejecimiento», es decir, el aumento del colectivo de población con edad superior a 80 años, que se ha duplicado en sólo veinte años. Estas cuestiones conforman una nueva realidad que conlleva problemas de dependencia en las últimas etapas de la vida para un colectivo de personas cada vez más amplio. A esta realidad, derivada del envejecimiento, debe añadirse la dependencia por razones de enfermedad y otras causas de discapacidad o limitación. Hasta ahora, han sido las familias, y en especial, las mujeres, las que tradicionalmente han asumido el cuidado de las personas dependientes, constituyendo lo que ha dado en llamarse el «apoyo informal».

Tal como indica en su Exposición de Motivos, los cambios en el modelo de familia y la incorporación progresiva de casi tres millones de mujeres, en la última década, al mercado de trabajo introducen nuevos factores que hacen imprescindible una revisión del sistema tradicional de atención para asegurar una adecuada capacidad de prestación de cuidados a aquellas personas. Sin duda, esta realidad social genera conflictos familiares, desde el momento en que hay una necesidad de dar respuesta económica, de colaboración en la asistencia, de dedicación de tiempo y en ocasiones, de expresión de afecto; todas ellas cuestiones de difícil abordaje en el procedimiento judicial y, por ello, se buscan espacios de diálogo donde tratar temas de familia con la propia familia.

Ley orgánica 3/2007, de 22 de marzo, para la igualdad efectiva de mujeres y hombres.

La Ley orgánica 3/2007 incorpora al ordenamiento español dos directivas en materia de igualdad de trato, la 2002/73/CE, de reforma de la Directiva 76/207/CEE, relativa a la aplicación del principio de igualdad de trato entre hombres y mujeres en lo que se refiere al acceso al empleo, a la formación y a la promoción profesionales, y a las condiciones de trabajo; y la Directiva 2004/II3/CE, sobre aplicación del principio de igualdad de trato entre hombres y mujeres en el acceso a bienes y servicios y su suministro.

La mayor novedad de esta Ley radica, con todo, en la prevención de esas conductas discriminatorias y en la previsión de políticas activas para hacer efectivo el principio de igualdad. Tal opción implica necesariamente una proyección del principio de igualdad sobre los diversos ámbitos del ordenamiento jurídico, de la realidad social y, sin duda, de todos aquellos procesos que faciliten la gestión de conflictos y la toma de decisiones.

Tal como recoge en su Exposición de motivos, «el logro de la igualdad real y efectiva en nuestra sociedad requiere no sólo del compromiso de los sujetos públicos, sino también de su promoción decidida en la órbita de las relaciones entre particulares», precisamente es en esas relaciones interpersonales y en los posibles conflictos que surjan donde tiene cabida los procesos de mediación. 
II.4. Ley Orgánica I/2004, de 28 de diciembre, de Medidas de Protección Integral contra la Violencia de Género

Actualmente, en la realidad española existe una especial conciencia sobre la violencia y agresiones contra las mujeres, gracias, en buena medida, al esfuerzo realizado por las organizaciones de mujeres en la lucha contra todas las formas de violencia de género. Tal como expresa esta ley, ya no es un «delito invisible», sino que produce un rechazo colectivo y una evidente alarma social.

Con este texto legal, se cumple con las recomendaciones internacionales en el sentido de proporcionar una respuesta global a la violencia. Para ello, el ámbito de la Ley abarca tanto aspectos preventivos, como educativos, sociales, asistenciales y de atención posterior a las víctimas. En su preámbulo indica que «desde el punto de vista judicial, se define esta violencia como un fenómeno complejo en el que es necesario intervenir desde diferentes perspectivas jurídicas». Teniendo en cuenta el objetivo de este trabajo, es en tales expresiones donde se vislumbra algún atisbo de reconocimiento de la necesidad de apostar por diversas actuaciones y procesos que garanticen el bienestar de la persona que está siendo víctima de esa violencia. Entre dichas perspectiva jurídicas en sentido amplio se sitúa la mediación, en la medida que se contemple ésta como un proceso de gestión de conflictos flexible y garantista de las necesidades, con la protección específica para evitar que las personas corran riesgos por participar en el proceso.

El objeto de la ley es «actuar contra la violencia, como manifestación de la discriminación, la situación de desigualdad y las relaciones de poder de los hombres sobre las mujeres...», con la finalidad de prevenir, sancionar y erradicar esta violencia. Para lograr dichos fines se hace referencia a medidas jurídicas, educativas y de asistencia social integral, entre las que podríamos incluir la mediación, si no fuera porque expresamente la ley veda esta posibilidad, a tenor de lo preceptuado en su artículo 44.5. Por tanto, a sensu contrario, se podría entender que en ausencia de violencia de género, la ley favorece la mediación.

La violencia de género a que se refiere esta ley, tal como indica en su artículo I.3., «comprende todo acto de violencia física y psicológica, incluidas las agresiones a la libertad sexual, las amenazas, las coacciones o la privación arbitraria de libertad», con lo cual al analizar la generalidad del concepto de violencia junto a la limitación absoluta de «en todos estos casos está vedada la mediación», no deja opción al desarrollo de la mediación, ni incluso a investigaciones que den luz a planteamientos progresistas e innovadores.

\section{Proyecto de ley de mediación en asuntos civiles y mercantiles}

El Proyecto de Ley cumple con la obligación de trasponer al ordenamiento jurídico español la Directiva 2008/52/CE del Parlamento Europeo y del Consejo de 2I de mayo de 2008 , sobre ciertos aspectos de la mediación en asuntos civiles y mercantiles; pero la regulación de la mediación que se desarrolla en el proyecto va más allá del contenido de la Directiva ya que el Gobierno aprovecha esta oportunidad para dar cumplimiento al mandato previsto en la Ley I5/2005, de 8 de julio, por la que se modifica el Código Civil y la Ley de Enjuiciamiento Civil en materia de separación y divorcio ${ }^{\mathrm{I} 8}$.

\footnotetext{
${ }^{18}$ En la Disposición Final Tercera de la ley citada se expresa: «El Gobierno remitirá a las Cortes un proyecto de ley sobre mediación basada en los principios establecidos en las disposiciones de la Unión Europea, y en todo caso en los de voluntariedad, imparcialidad, neutralidad y confidencialidad y en el respeto a los servicios de mediación creados por las Comunidades Autónomas».
} 
Si bien actualmente son I3 las comunidades autónomas que han regulado, en el ámbito de sus competencias, la mediación familiar, no existe en nuestro ordenamiento jurídico una norma que, con carácter general, ponga en conexión la mediación con la jurisdicción lo que, en la práctica, limita la eficacia real de aquella, siendo éste el propósito principal del proyecto de ley.

\section{III.I. Concepto de mediación}

El proyecto introduce un concepto de mediación que se caracteriza por ser autónomo al procedimiento judicial. Tal como cita expresamente la Exposición de Motivos es «una fórmula extraprocesal que se proyecta en conflictos de diversa indole». A continuación, en el artículo I del proyecto se define la mediación como «aquel medio de solución de controversias en que dos o más partes intentan voluntariamente alcanzar por sí mismas un acuerdo con la intervención de un mediador».

La peculiaridad de esta definición se encuentra, como decíamos, en su carácter extrajudicial y que es intervenida por una persona que no se sitúa por encima de las partes y del que se espera una intervención activa ${ }^{\mathrm{I}}$ en pos de la solución de la controversia. Contrariamente a lo que se pueda pensar, esa intervención «activa» de la persona mediadora, de la que hablaremos al comentar el principio de neutralidad, no choca con la forma autocompositiva de resolver las controversias que caracteriza el procedimiento de mediación, ya que siempre y en todo caso la solución de la controversia la aportan las partes, a diferencia de los medios heterocompositivos (juicio o arbitraje) en los cuales el juez o arbitro, respectivamente, deciden e imponen un resultado a favor de una de las partes.

En definitiva, para el proyecto el instituto de la mediación se debe constituir como «un procedimiento informal $y$ privado de solución de diferencias» en contraposición a los procedimientos formales y públicos.

III.2. Voluntariedad, tutela judicial efectiva y principio dispositivo en su vertiente sustantiva y adjetiva

Si como habíamos manifestado anteriormente, la libertad y autonomía de la persona para regular sus propios intereses se configuran como los principios rectores de la mediación, otro de los grandes principios que forma parte del procedimiento mismo de este instituto es el de voluntariedad. La consecuencia más inmediata derivada de este principio se encuentra en íntima conexión con el derecho a la tutela judicial efectiva (art. 24.I CE). Es decir, nadie estará obligado a recurrir al proceso de mediación cómo vía de resolución de sus controversias de manera alternativa a la vía judicial, ya que, de ser así se estaría vulnerando el derecho constitucional de todas las personas a obtener el amparo judicial.

Por tanto, una vez realizada la reflexión sobre la tutela judicial efectiva, entendemos que el principio de voluntariedad es compatible con la obligación de intentar la mediación como fase previa a acudir a la vía judicial, como en su momento fue obligatorio acudir a la conciliación civil como fase previa a interponer una demanda contenciosa. Y así lo ha entendido el prelegislador al incluir en el proyecto de ley la obligatoriedad de iniciar la

\footnotetext{
I9 En la Exposición de Motivos del proyecto se dice: «La pieza esencial del modelo es la figura del mediador, pues a él corresponde facilitar y encontrar una solución dialogada y voluntariamente aceptada por las partes». En otro apartado expresa, refiriéndose a quien media: «del que se pretende una actitud positiva orientada a la solución de la controversia, a diferencia de otras figuras, como la conciliación, en la que la participación de un tercero se produce con una limitada implicación o capacidad de propuesta».
} 
mediación «....cuando lo prevea la legislación procesal» ${ }^{20}$ (art. 7.I) o cuando exista entre las partes en conflicto un previo «pacto por escrito que exprese el compromiso de someter a mediación las controversias surgidas...» (art.7.2); es mas, en aquellos procedimientos en los que el inicio de la mediación no es impuesta por ley ${ }^{2 \mathrm{I}}$, el proyecto compromete al juez para que tenga la iniciativa en poner a disposición de las partes una mediación extrajudicial. Así lo establece la propuesta de reforma del apartado I del artículo 4I4 de la Ley de Enjuiciamiento Civil: «En esta convocatoria se informará a las partes de la posibilidad de recurrir a la mediación para intentar solucionar el conflicto, en cuyo caso éstas indicarán en la audiencia su decisión al respecto y las razones de la misma... », y todo ello con una clara intención de acercar y dar a conocer las posibilidades que ofrece este procedimiento complementario al sistema judicial en línea con los postulados de la Directiva ${ }^{22}$ que el proyecto del ley incorpora al derecho español.

El principio de voluntariedad tiene su significado entonces, en la posibilidad o no para las partes de mantener la mediación una vez iniciado el proceso, y sobre todo en la consecución de un acuerdo, que sólo puede darse si ambas partes consienten en aceptarlo; lo que entronca con el principio de libre disposición al que el proyecto de ley hace alusión en el enunciado ${ }^{23}$ del artículo 7 y que se concreta en la disponibilidad por las partes del proceso de mediación. Voluntariedad y libre disposición, entendidas aquí de forma sinónima, tienen su reflejo en el proyecto de ley cuando se establece que «nadie está obligado a concluir un acuerdo ni a mantenerse en el procedimiento de mediación», (art.7.3) y se reafirma en el artículo 23, en el que se otorga la posibilidad de que el procedimiento de mediación finalice «porque todas o alguna de las partes ejerzan su derecho a dar por terminadas las actuaciones».

El proyecto de ley también se refiere al principio dispositivo ${ }^{24}$, principio informador de nuestro derecho procesal civil, y a materias indisponibles para las partes ${ }^{25}$. Entendemos que ambos guardan relación con el principio de voluntariedad como expresión última de la autonomía de la voluntad que rige las relaciones de derecho privado, de ahí su tratamiento conjunto, ya que para que el acuerdo de mediación despliegue los efectos jurídicos recogidos en la norma ${ }^{26}$, no basta la mera voluntad de las partes en la consecución

${ }^{20}$ En la Disposición Final Cuarta del proyecto de ley se prevé la siguiente modificación de la Ley I/2000, de 7 de enero, de Enjuiciamiento Civil: Apartado Io. «El apartado 3 del artículo 437 pasa a ser el 4 y se introduce un nuevo apartado 3 con la siguiente redacción:

3. En los juicios verbales a los que alude el apartado 2 del artículo 250 que consistan en una reclamación de cantidad, no se refieran a alguna de las materias previstas en el apartado 1 del mismo artículo y no se trate de una materia de consumo, será obligatorio el intento de mediación de las partes en los seis meses anteriores a la interposición de la demanda.»

${ }^{2 \pi}$ Según se expresa en la Exposición de Motivos del Proyecto «Para impulsar la utilización de este instituto la ley exige acudir a la mediación en determinados casos como requisito necesario y previo al proceso o a otro procedimiento extrajudicial de resolución de conflictos. En particular, así se hace en el ámbito de las reclamaciones de cantidad».

${ }^{22}$ Directiva 2008/52/CE del Parlamento Europeo y del Consejo, de 2I de mayo de 2008. Considerando (I3) «La mediación a que se refiere la presente Directiva debe ser un procedimiento voluntario, en el sentido de que las partes se responsabilizan de él y pueden organizarlo como lo deseen $y$ darlo por terminado en cualquier momento.

No obstante, el Derecho nacional debe dar a los órganos jurisdiccionales la posibilidad de establecer límites temporales al procedimiento de mediación; por otra parte, también deben poder señalar a las partes la posibilidad de la mediación, cuando resulte oportuno».

${ }^{23}$ Artículo 7. Voluntariedad y libre disposición.

3. Nadie está obligado a mantenerse en el procedimiento de mediación ni a concluir un acuerdo.

${ }^{24}$ Según se expresa en la Exposición de Motivos del Proyecto «Se regula la facultad de las partes para disponer del objeto del juicio y someterse a mediación...».

${ }^{25}$ Artículo 2. Ámbito de aplicación.

I. Esta ley, con los efectos procesales que de ella derivan, es de aplicación a las mediaciones en asuntos civiles o mercantiles, incluidos los conflictos transfronterizos, siempre que no afecten a derechos y obligaciones que no estén a disposición de las partes en virtud de la legislación aplicable.

${ }^{26}$ El párrafo segundo del Artículo I del proyecto de ley afirma: «Sólo las mediaciones desarrolladas con arreglo a esta ley producirán los efectos procesales que en ella se establecen». 
del acuerdo, sino que el objeto del conflicto debe constituir una materia disponible para las mismas. Lo anterior viene a colación a propósito de la mediación familiar, ya que no debe existir duda en que la mediación sobre esta materia se encuentra dentro del ámbito de aplicación de la norma, puesto que los negocios jurídicos de derecho de familia son asuntos civiles y además la norma hace referencia expresa al afirmar en el artículo 8: «En la mediación familiar se debe tener presente el interés superior del menon», pero aunque esto es así, no podemos olvidar que la autonomía de la voluntad en materia de familia se encuentra más restringida que en el resto del derecho privado. Muchas de las normas reguladoras de esta institución son de ius cogens. De ahí que muchas veces los derechos y deberes se impongan con independencia de la voluntad de quienes están sujetos a la norma, es decir, las partes no pueden disponer o regular libremente determinadas materias ${ }^{27}$, lo cual no significa que todos los asuntos de derecho de familia sean indisponibles ${ }^{28}$ y que se encuentren al margen del proyecto de ley.

Por ello, aunque la esencia de la norma sea siempre dejar a salvo la facultad de las partes para disponer del objeto del juicio y someterse a mediación, tal como establece la propuesta de reforma del apartado i del artículo ig de la Ley de Enjuiciamiento Civil ${ }^{29}$, esta facultad para disponer del objeto del juicio tiene sus límites, ya que el concepto objeto del juicio incluye la relación sustantiva que se articula en la pretensión procesal, siendo la posibilidad de disponer o no de esta relación sustantiva la que permite concluir un proceso por medio de la autocomposición sin necesidad de una sentencia. Por el contrario, cuando la relación sustantiva tiene por objeto materias no disponibles, el poder de disposición de las partes interesadas sobre el objeto del juicio aún estando conformes, se halla abolido o limitado. Los sujetos jurídicos deben necesariamente seguir la vía judicial, en cuanto que el efecto jurídico no puede alcanzarse, -aún cuando las partes estén de acuerdo-, sino a través de la sentencia del juez (Calamandrei ig62).

\section{III.3. Principio de neutralidad}

Ya habíamos comentado al hablar del concepto de mediación (vid. supra), que la ley atribuye al mediador una intervención activa en el proceso de mediación en pos de la solución de la controversia, así, al tratar de las obligaciones del mediador, el art. I4.2 del proyecto establece que «El mediador desarrollará una conducta activa tendente a lograr el acercamiento entre las partes, con respeto a los principios recogidos en esta ley». A la vista de este planteamiento, la cuestión se debe de centrar entonces en analizar si a la luz de este precepto nos encontramos con un oxímoron, ya que en principio parece tener difícil encaje la conducta activa del mediador con el principio de neutralidad, que la norma se abstiene de definir a pesar de dedicarle al artículo 9. A este principio no hace alusión la Directiva y la Ley $15 / 2005$, de 8 de julio aunque lo menciona en su Exposición de Motivos y en la Disposición Final tercera ${ }^{30}$, tampoco lo define.

${ }_{27}$ Las referidos a cónyuge, hijos o interés familiar más necesitado de protección art. 90, párrafo 2, y 103 reglas primera y tercera del Código Civil.

${ }^{28}$ Son materias disponibles las referidas, por ejemplo, al patrimonio de los cónyuges, a la pensión compensatoria...etc.

${ }^{29}$ El I del artículo ig de la Ley de Enjuiciamiento Civil que quedaría redactado en los siguientes términos: «I. Los litigantes están facultados para disponer del objeto del juicio y podrán renunciar, desistir del juicio, allanarse, someterse a mediación o a arbitraje y transigir sobre lo que sea objeto del mismo, excepto cuando la ley lo prohíba o establezca limitaciones por razones de interés general o en beneficio de tercero.»

${ }^{30}$ Exposición de Motivos Ley I5/2005, de 8 de julio «...se establece la mediación como un recurso voluntario alternativo de solución de los litigios familiares por vía de mutuo acuerdo con la intervención de un mediador, imparcial y neutral», y Disposición Final Tercera «El Gobierno remitirá a las Cortes un proyecto de ley sobre mediación basada en los principios establecidos en las disposiciones de la Unión Europea, y en todo caso en los de voluntariedad, imparcialidad, neutralidad y confidencialidad...». 
Estamos, sin lugar a dudas ante un principio complejo en su significado y controvertido en su aplicación, que para muchos autores y normas se yuxtapone al principio de imparcialidad.

La Recomendación $N^{\circ} \mathrm{R}\left(9^{8}\right)$ I del Consejo de Europa, ya citada, se refiere a que «el mediador es neutral respecto al resultado del proceso de mediación», es decir acota la neutralidad al resultado del proceso, no al proceso mismo, por lo que a tenor de esta consigna el papel activo de la persona mediadora que propugna el proyecto de ley no sería incompatible con el principio de neutralidad encontrándose su estrategia de trabajo en la línea de la intervención evaluative siguiendo la clasificación que Riskin (2003) hace respecto del papel que juega quien actúa en el proceso de mediación. Para este autor el mediador evaluative asume que las partes quieren y necesitan que se les provea tanto de orientación como de conocimiento -basados en la ley, la práctica o la tecnología- y de las que la persona mediadora se encuentra cualificada para proporcionar esa orientación y conocimientos de acuerdo con su entrenamiento, experiencia y objetividad. Por el contrario, la intervención facilitative asume que las partes son capaces de trabajar con la contraparte y capaces de comprender sus situaciones mejor que quien, y quizás mejor que sus representantes legales. En consecuencia, quienes protagonizan el conflicto pueden crear mejores soluciones que la persona que interviene como mediadora. Por tanto, el modelo facilitative asume que su principal misión es la de clarificar y mejorar la comunicación entre las partes para ayudarles a decidir qué hacer.

III.4. Finalización del proceso. El acuerdo y su ejecutividad.

El proceso de mediación concluye con la redacción por el mediador del acta final. Dicho documento está integrado por lo que podríamos denominar una parte formal que necesariamente deberá contener la identidad de las partes y del mediador e indicar si el proceso ha finalizado con o sin acuerdo; en este último caso se deberá reflejar además el motivo de la falta de acuerdo, debiéndose concretar en alguno de los siguientes supuestos ${ }^{3 \mathrm{I}}$ :

- Haber transcurrido el plazo máximo previsto para la duración del procedimiento (dos meses, según el artículo 2I).

- La voluntad de una o todas las partes de concluir el proceso.

- La valoración de la persona mediadora sobre:

- Posiciones irreconciliables de las partes.

- Concurrencia de cualquier otra causa.

Si el proceso ha finalizado con acuerdo, el acta final estará además integrada por una parte material constituida por los acuerdos propiamente dichos, redactados por la persona mediadora de forma clara $y$ comprensible ${ }^{32}$. Pero estos acuerdos contenidos dentro del acta final no deben confundirse con lo que la norma denomina acuerdo de mediación ${ }^{33}$, ya que, por el mismo debemos entender aquel documento que, redactado por los intervinientes en el proceso o sus asesores de conformidad con lo recogido en el acta final, revistiendo todas las formalidades que la ley prescribe, es de obligado cumplimiento para las partes, reconociéndole la norma como uno de los títulos que llevan aparejada ejecución

\footnotetext{
${ }^{3 \mathrm{I}}$ De conformidad con lo regulado en el artículo 23 del Proyecto de Ley.

${ }^{2}$ De conformidad con lo establecido en el apartado 3 del artículo 23 del Proyecto de Ley.

${ }^{33}$ Según se expresa en el artículo 24 del Proyecto de Ley.
} 
forzosa, sin otras formalidades adicionales que las descritas en la norma ${ }^{34}$, ya que la ley confiere al acuerdo de mediación la fuerza de cosa juzgada entre las partes ${ }^{35}$. De ahí que, pese al carácter no jurisdiccional de la mediación, el acuerdo se encuentre revestido de auctoritas, por lo que los efectos del mismo, se asimilen a los que tendrían una sentencia judicial ${ }^{36}$.

Por último, relacionado con la finalización y el sentido del procedimiento de mediación, éste puede tener dos consecuencias que no tienen por qué ser excluyentes entre sí: conseguir mejorar las relaciones entre las partes, ya que en palabras de la Exposición de Motivos «...alcanzar un acuerdo no es algo obligatorio, pues, a veces, como enseña la práctica, la mediación sirve para mejorar relaciones», y que éstas alcancen acuerdos bien sean totales o parciales.

Para valorar el éxito del proceso de mediación se debe de tener en cuenta, además de la consecución misma de los acuerdos, el cumplimiento voluntario de los mismos, que será una consecuencia del proceso de mediación ya que el mismo debe ir encaminado a ayudar a las personas a «... comprender el origen de sus diferencias, a conocer las causas $y$ consecuencias de lo ocurrido, a confrontar sus visiones $y$ a encontrar soluciones para resolverlas» según se manifiesta en la Exposición de Motivos. Asimismo, la bondad de la mediación no se debe de medir tanto en el número de personas que han conseguido solucionar sus controversias a través de la misma, como en el número de cumplimientos voluntarios de esos acuerdos, que debería ser superior al cumplimiento voluntario de las resoluciones judiciales. A su vez, como consecuencia del planteamiento de la mejora de las relaciones interpersonales, el simple hecho de facilitar la comunicación entre las partes enfrentadas sería considerado un éxito del proceso.

\section{III.5. Formación de la persona mediadora}

Tal y como hemos examinado, el proyecto de ley apuesta por un tipo de intervención mediadora que trabaje con las partes para ayudarlas a conseguir el acuerdo, y ello implica necesariamente la presunción de que la persona mediadora posea los conocimientos necesarios para ponerlos a disposición de las partes con el objeto de que estas puedan culminar acuerdos viables desde el punto de vista jurídico y desde el punto de vista de la situación personal del obligado a cumplirlos, ya que sería baldío y perjudicial para las partes trabajar por un compromiso que no contemple su situación real y que por ende sea de cumplimiento imposible o poco factible; así pues, el acuerdo se debe adecuar al binomio posibilidad real -viabilidad jurídica y será quien media la encargada de velar porque esto sea así, aún cuando no existe un mandato expreso en este sentido en la ley, ya que la norma no impone la intervención de terceras partes asesoras que puedan

\footnotetext{
${ }^{34}$ Según refiere el Artículo 24 del Proyecto de Ley:

«En el acuerdo de mediación deberá constar la identidad y el domicilio de las partes, el lugar y fecha en que se suscribe, las obligaciones que cada parte asume y que se ha seguido un procedimiento de mediación ajustado a las previsiones de esta ley, con indicación del mediador o mediadores que han intervenido y, en su caso, de la institución de mediación en la cual se ha desarrollado el procedimiento.

2. El acuerdo de mediación deberá firmarse por las partes o sus representantes y presentarse al mediador, en el plazo máximo de diez días desde el acta final, para su firma».

35 El apartado 4 del artículo 24 dice: «El acuerdo de mediación produce efectos de cosa juzgada para las partes y frente a él sólo podrá solicitarse la anulación».

${ }^{36}$ Por analogía con los efectos del laudo arbitral, puede ser de aplicación para el acuerdo de mediación el razonamiento contenido en el ATC 326/1993, de 28 de octubre, en el que se expresa «el árbitro que zanja una controversia mediante un laudo de Derecho actúa en ejercicio de una potestad de iuris dictio, pues el arbitraje es un 'equivalente jurisdiccional', mediante el cual las partes pueden obtener los mismos objetivos que con la jurisdicción civil, esto es, una decisión que ponga fin al conflicto con todos los efectos de la cosa juzgada (SSTC 62/I99I, F.J. $5^{\circ}$, y $288 /$ I993, F.J. $3^{\circ}$ ). Su declaración de los derechos y obligaciones recíprocas de las partes de la controversia se encuentra revestida de auctoritas, por imperativo de la Ley; y sólo carece del imperium necesario para ejecutar forzosamente su decisión, que la ley vigente reserva a los Tribunales civiles».
} 
permanecer al lado de sus protagonistas durante el proceso de mediación ni en la fase de redacción de los acuerdos, aunque lo deseable sería que las partes recibiesen en todo momento el asesoramiento profesional adecuado a su problemática.

Es este sin duda el punto débil del proyecto de ley, ya que, los ambiciosos objetivos de la norma y la gran apuesta por el valor y eficacia de los acuerdos pueden ir al traste si no se garantiza la competencia profesional de los mediadores. El mero requisito de estar en posesión de un título oficial universitario o de educación profesional superior, según expresa el artículo I2 del proyecto, no garantiza la competencia profesional de quien media, sin que la recomendación contendida en la Directiva 2008/52/CE de 2I de mayo de 200837 , haya sido desarrollada adecuadamente por el proyecto, limitándose este a reproducir la declaración de intenciones contenida en la Directiva, las Administraciones públicas competentes, en colaboración con las instituciones de mediación, fomentarán la adecuada formación inicial y continua de los mediadores (artículo I3), sin regular mecanismos concretos para la correcta formación de los profesionales de la mediación.

Sería deseable, siguiendo la línea de la Recomendación $\mathrm{N}^{\circ} \mathrm{R}\left(9^{8}\right) \mathrm{I}^{3^{8}}$, que la futura ley o su desarrollo reglamentario contuviera criterios que garantizasen una selección de personas mediadoras con una adecuada formación y cualificación, así como respeto a un código deontológico que garantice los principios básicos de tal intervención.

\section{Regulación autonómica en mediación familiar: principios reguladores y límites}

La mediación familiar ha sido objeto de regulación normativa autonómica, estando vigentes en la actualidad trece leyes y algunas Comunidades Autónomas se encuentran en fase de elaboración de un borrador de proyecto de ley de mediación (Comunidad de La Rioja, Comunidad de Navarra, Región de Murcia).

Desde que en el año 200I viera la luz la primera ley de mediación familiar en Cataluña ${ }^{39}$, han sido varias comunidades autónomas $\left(\right.$ Galicia $^{40}$, Valencia ${ }^{4 \mathrm{I}}$, Canarias ${ }^{42}$, Castilla-La Mancha ${ }^{43}$, Castilla y León ${ }^{44}$, Islas Baleares ${ }^{45}$, Madrid ${ }^{46}$, Asturias ${ }^{47}$, País Vasco ${ }^{48}$,

${ }^{37}$ En el artículo 4.2 de la citada Directiva se recoge: «Los Estados miembros fomentarán la formación inicial y continua de mediadores para garantizar que la mediación se lleve a cabo de forma eficaz, imparcial y competente en relación con las partes».

$3^{8}$ En la letra c) del apartado II de los PRINCIPIOS SOBRE LA MEDIACION FAMILIAR, de la Recomendación citada se expresa: «Sin perjuicio de la forma en la que la mediación esté organizada y puesta en funcionamiento los Estados deberían velar para que existan mecanismos adecuados que aseguren su existencia: procedimientos para la selección, la formación y la cualificación de los mediadores, las normas de 'buena práctica' que deben ser elaboradas y seguidas por los mediadores».

39 Ley $15 / 2009$, de 22 de julio, de mediación en el ámbito del derecho privado en Cataluña (BOE I98, I7/08/2009, DOGC 5432, 30/07/2009), que deroga la Ley I/200I, de I5 de marzo, de mediación familiar de Cataluña $\left(B O E \mathrm{n}^{\circ}\right.$ 9I, de $\mathrm{I} 6$ de abril de 200I). 200I).

$4^{\circ}$ Ley 4/200I, de 3I de mayo, reguladora de la mediación familiar de Galicia (BOE $\mathrm{n}^{\circ}$ I57, de 2 de julio de

${ }^{41}$ Ley 7/200I, de 26 de noviembre, reguladora de la Mediación Familiar en el ámbito de la Comunidad Valenciana (BOE $\mathrm{n}^{\circ}$ 303, de I9 de diciembre de 200I).

$4^{42}$ Ley I5/2003, de 8 de abril, de la mediación familiar (BOE $\mathrm{n}^{\circ}$ I34, de 5 de junio de 2003); modificada por la Ley canaria $3 / 2005$, de 23 de junio ( $B O E \mathrm{n}^{\circ} \mathrm{I} 77$, de 26 de julio de 2005 ).

${ }^{43}$ Ley 4/2005, de 24 de mayo de 2005, del Servicio Social Especializado de Mediación Familiar de Castilla la Mancha (BOE $\mathrm{n}^{\circ}$ 203, de 25 de agosto de 2005).

${ }^{44}$ Ley I/2006, de 6 de abril, de Mediación Familiar de Castilla y León (BOE n ${ }^{\circ}$ I05, de 3 mayo de 2006).

${ }^{45}$ Ley $18 / 2006$, de 22 de noviembre, de mediación familiar de las Islas Baleares $\left(B O E \mathrm{n}^{\circ} 303\right.$, de 20 de diciembre de 2006). 
Andalucía $^{49}$ y Cantabria ${ }^{50}$ ) las que en el ejercicio de sus competencias han desarrollado legislativamente esta materia tomando la mayoría de ellas como base la «protección social, económica y jurídica de la familia», tal como se expresa en el artículo 39.I de la Constitución Española. Y todas las leyes han tenido como referente inmediato la Recomendación $\mathrm{N}^{\circ} \mathrm{R}$ (98)I del Consejo de Europa.

La relevancia de la mediación se pone asimismo de manifiesto en el hecho de que en la redacción de los nuevos Estatutos de Autonomía de Cataluña y Andalucía se recojan y precisen las competencias autonómicas en mediación ${ }^{5 \mathrm{I}}$, y que en el País Vasco se regule la aplicación de la mediación a los asuntos relacionados con los alquileres y la propiedad horizontal ${ }^{52}$, amén de la ampliación de la mediación a las materias civiles que hace la nueva Ley de Mediación de Cataluña ${ }^{53}$.

El interés que ha generado la mediación como proceso constructivo de gestión de conflictos, así como la necesidad de control de esta actividad profesional, han dado como resultado leyes diversas en cuanto a su extensión, estructura y contenido y, en cierta medida, con cierta similitud en lo referente a los conceptos que definen los principios generales y los límites de la intervención en mediación.

El interés de proceder a un análisis detallado de las leyes autonómicas de mediación se centra en identificar el discurso que subyace a cada uno de los textos legales, teniendo en cuenta que todos partieron de una misma Recomendación europea, R (98)I, y todas ellas la han interpretado según sus parámetros, plasmando los principios y límites del proceso de mediación acorde con el desarrollo local y el movimiento asociativo y profesional dominante.

El análisis del contenido de la legislación específica sobre mediación se ha realizado a partir de cinco categorías o unidades de análisis: I. Imparcialidad; 2. Neutralidad; 3. Carácter personalísimo, inmediatez o no representación; 4. Flexibilidad del proceso; 5 . Ausencia de violencia.

La identificación de estas categorías como unidades de análisis tiene concordancia con los principios que generan, con frecuencia, dilemas éticos en la intervención directa en los procesos de mediación, tal como se refleja en la parte empírica, correspondiente al estudio cualitativo de la investigación de Merino (2OII). Por tanto, se ha considerado necesario conocer el discurso legal autonómico sobre la mediación, sus principios y límites,

${ }^{46}$ Ley I/2007, de 2I de febrero, de Mediación Familiar de la Comunidad de Madrid (BOE ${ }^{\circ}$ I53, de 27 de junio de 2007).

47 Ley 3/2007, de 23 de marzo, de Mediación Familiar de Asturias (BOE nº I70, de I7 de julio de 2007).

${ }^{48}$ Ley I/2008, de 8 de febrero, de Mediación Familiar del País Vasco (BOPV de I8 de febrero de 2008).

49 Ley I/2009, de 27 de febrero, de Mediación Familiar de Andalucía (BOJA nº 50, de I3 de marzo de 2009).

${ }^{50}$ Ley I/20II, de 28 de marzo, de Mediación Familiar de Cantabria (BOC n ${ }^{\circ}$ 66, de 5 de abril de 20II)n

${ }^{51}$ El artículo ro6.2 del Estatuto Autonomía de Cataluña aprobado por Ley orgánica 6/2006, de i9 de julio, $\left(B O E \mathrm{n}^{\circ} \mathrm{I72}\right.$, de 20 de julio de 2006) expresa: «La Generalitat puede establecer los instrumentos y procedimientos de mediación y conciliación en la resolución de conflictos en las materias de su competencia»; de igual forma dispone el artículo 150.2 del Estatuto de Autonomía de Andalucía aprobado por Ley Orgánica 2/2007, de I9 de marzo, (BOE $\mathrm{n}^{\circ}$ 68, de 20 de marzo de 2007).

$5^{2}$ Orden de 24 de octubre de 2007 , del Consejero de Vivienda y Asuntos Sociales de Euskadi, por la que se regulan las funciones de mediación y conciliación en materia de propiedad horizontal y arrendamientos urbanos $\left(B O P V \mathrm{n}^{\circ} 222\right.$, de I9 de noviembre de 2007).

${ }^{53}$ Ley I5/2009, de 22 de julio, de mediación en el ámbito del derecho privado en Cataluña. Artículo $2 \mathrm{n}^{\circ} 2$. «La mediación civil a la que se refiere la presente ley comprende cualquier tipo de cuestión o pretensión en materia de derecho privado que pueda conocerse en un proceso judicial y que se caracterice porque se haya roto la comunicación personal entre las partes, si estas deben mantener relaciones en el futuro...». 
para avanzar en su reconceptualización, ya que se trata tanto de aspectos de trascendencia ética, como de calidad profesional de la intervención.

Este análisis realizado en el citado estudio, parte de la extracción de la información relevante a partir de la plantilla de unidades de análisis, lo cual facilitó el trabajo de sistematización a partir de una estructura diferente. En todas las leyes se contempla la mediación como un mecanismo por el cual las partes en conflicto colaboran para autocomponer la solución al conflicto. No obstante se aprecian ciertas divergencias.

\section{Imparcialidad}

Este principio, según el discurso de las leyes autonómicas, implica que la persona mediadora no debe tener preferencia o favoritismos hacia una $u$ otra parte; es decir, debe guardar el equilibrio entre las dos posturas en controversia. De modo, que cuando no sea posible, debe producirse la abstención. Se regula este principio en las trece leyes, tal como consta en la tabla comparativa.

\section{Neutralidad}

Según el diccionario de la R.A.E. (Real Academia Española), neutral «es aquel que no es de ni de uno ni de otro, que entre dos partes que contienden, permanece sin inclinarse a ninguna de ellas». Por lo tanto, este principio implica que la persona mediadora no debe orientar ni imponer sus valores o principios, sino que debe respetar los principios, valores, cultura y opiniones de las dos partes. No obstante, como se ha puesto de manifiesto en este estudio, este principio es complejo, ya que no es posible intervenir en una interacción, sin contribuir de alguna manera a darle forma. Aún siendo cuestionable su aplicabilidad, se reconoce como principio en la totalidad de leyes autonómicas.

En algunas leyes se observan peculiaridades, por ejemplo: en la ley valenciana, artículo 9 g) se confunde este principio de neutralidad con la autocomposición. En otras leyes se observa cierta evolución, sin que ello vaya a dar contenido práctico a este concepto. Por ejemplo, en la primera Ley de Illes Balears de 2006 se permitía ofrecer propuestas de solución (art. 2c), sin embargo, en la actual Ley I4/2010, se refiere a la neutralidad (art. 2c) como la función de ayudar a conseguir la conciliación de los sujetos sin imponer criterios propios en la toma de decisiones. En la Ley del Principado de Asturias, art. 5, junto a la neutralidad se reconoce la función de velar por el equilibrio entre las partes. En la Ley gallega se expresa que la persona mediadora «preservará su igualdad en la negociación, absteniéndose de promover actuaciones que comprometan su necesaria neutralidad» (art.8.2).

\section{Carácter personalísimo, inmediatez o no representación}

Este principio hace referencia a la necesidad de ser protagonista en la mediación, de forma directa, sin intermediarios ni representantes. Este aspecto es contemplado por todas las leyes, bien de forma explícita o implícita. Entre las particularidades, la ley valenciana no lo regula expresamente pero en sus artículos 8 y iо habla de inmediatez y colaboración de las partes respectivamente. La ley de Castilla La Mancha, hace referencia a esa intervención personal de los interesados en su artículo I9. La ley de Castilla y León lo recoge en el artículo 4.8. El antiguo artículo $2 \mathrm{f}$ ) de la Ley balear, así como el nuevo, tratan del principio de la inmediatez, mediante el que se impone el deber de asistir personalmente a las partes, prohibiendo expresamente la utilización de representantes o personas que hagan de intermediarias. El artículo 4 e) de la Ley madrileña, es similar a la redacción de la Ley balear. El art 8 de la Ley asturiana habla de la inmediación, y utiliza una redacción similar a la balear y madrileña; sin embargo, prevé que excepcionalmente se usen medios electrónicos, siempre y cuando se garantice la identidad de la persona mediadora y de las 
partes. No obstante, es inexcusable la presencia física de las partes a la hora de firmar los acuerdos adoptados.

\section{Flexibilidad del proceso.}

Dada la naturaleza y objeto de la mediación familiar, este principio constituye una clara ventaja frente al procedimiento judicial, donde la ley establece de modo rígido las fases, plazos y forma de cada una de las actuaciones; lo que en ocasiones se convierte en obstáculo para la solución consensuada del proceso.

Este principio lo contemplan todas las leyes de forma específica, utilizando el concepto de flexibilidad o términos afines como es el caso de la ley canaria, que en su artículo 4.2 expresa que «la mediación familiar se ha de desarrollar sin sujeción a procedimiento reglado alguno ...»; la Ley de Castilla León que habla de sencillez y celeridad en el procedimiento de mediación; la ley asturiana en su preámbulo habla de instrumento informal y normas mínimas de funcionamiento; o la Ley de Castilla-La Mancha que hace referencia a la profesionalidad de la persona mediadora y, de este modo, deja a criterio profesional la gestión del proceso. En la Ley catalana de 2009 no se menciona expresamente este principio, al contrario que su primer texto legal de 200 I que sí lo especificaba.

\section{Ausencia de violencia}

Este aspecto ha generado gran polémica tanto a defensores como a detractores de la mediación. En general, se ha asumido que la mediación familiar, tal como se configura en las leyes autonómicas, no puede realizarse si las partes en conflicto no están en un plano de igualdad y equilibrio. De tal forma que en los supuestos de violencia o clara superioridad o imposición de una parte sobre otra, se debe buscar a través de la terapia o asesoramiento restablecer dicha igualdad para, posteriormente, iniciar el proceso de mediación familiar. Con este planteamiento el artículo 44.5 de la L.O. I/2004, limita absolutamente la mediación en casos de violencia.

Al analizar las leyes autonómicas con el fin de detectar la mención de la violencia como límite a la intervención en mediación, se han encontrado resultados diversos. Las primeras leyes aprobadas (Galicia, Valencia, Canarias) no mencionan específicamente la violencia. Sin embargo, este límite se deduce del articulado en cuanto a que la persona mediadora puede dar por interrumpida la mediación si no trata de asuntos mediables conforme a derecho.

La Ley de Castilla La Mancha prohíbe la intervención ante la existencia de malos tratos (artículo I7). En la Ley de Castilla y León, en el art. 4.5, excluye de la mediación todas aquellas situaciones en las que exista violencia o maltrato. En la primera Ley balear I8/2006 no se mencionaba expresamente la violencia, aunque se podía interpretar de forma indirecta, al establecer como excepción al principio de confidencialidad (artículo i6.2) que «exista amenaza para la integridad física o psíquica de una persona». En la vigente Ley Balear I4/20Io, en su art. 4.4.especifica el límite a la mediación de aquellos casos en los que se produzca violencia o malos tratos, o cualesquiera otras actuaciones que puedan ser constitutivas de ilícito penal. La Ley de la Comunidad de Madrid, en el art. 8.2, hace referencia al criterio de la persona mediadora a la hora de decidir abordar o no esa situación sin citar de forma literal la violencia, como factor excluyente de la mediación. La ley asturiana en su Disposición Adicional única remite a lo dispuesto en la LO I/2004 de 28 de diciembre. La ley vasca impide la mediación en estos supuestos, art. 5.4 ${ }^{\circ}$. En Andalucía al establecer la finalidad de la mediación, en su artículo 2.I, entiende por mediación familiar «el procedimiento extrajudicial de gestión de conflictos no violentos». 
En Cataluña la Ley I5/2009 amplía el marco de actuación al Derecho Privado y refuerza los límites de la mediación ante el desequilibrio de poder y la violencia. En su art. 6.I establece que «si es preciso, debe interrumpir el procedimiento de mediación mientras la igualdad de poder y la libertad de decidir de las partes no esté garantizada, especialmente como consecuencia de situaciones de violencia. En todo caso, se debe interrumpir o si procede paralizar, el inicio de la mediación familiar, si está implicada una mujer que ha sufrido o sufre cualquier forma de violencia machista en el ámbito de la pareja o en el ámbito familiar objeto de la mediación». Asimismo, en el art. I4.b) entre los deberes de la persona mediadora expresa que «se debe prestar una atención particular a cualquier signo de violencia, física o psíquica, entre las partes $\gamma$, si procede, denunciar el hecho a las autoridades judiciales».

La aprobación de la ley de mediación de Cantabria y Aragón (ambas publicadas en sus respectivos Boletines Oficiales la primera semana de abril de 20II), casi simultáneas a la aprobación del Proyecto de Ley de Mediación estatal por el Consejo de Ministros, han supuesto una evolución significativa en algunos aspectos de la mediación como proceso de resolución de conflictos con carácter extrajudicial e intrajudicial, con un ámbito amplio de aplicación. Sin embargo, en la línea de investigación de este trabajo y, en concreto en el análisis de contenido de la regulación normativa, se han detectado una serie de paradojas que entendemos han perdido la oportunidad de reflejar la evolución social y profesional que la mediación ha protagonizado en la última década.

La Ley de Cantabria I/20II, de 28 de marzo, define la mediación como una forma de resolución extrajudicial de conflictos entre personas, caracterizada por la intervención de una persona neutral e imparcial. En su artículo 6, hace mención expresa a estos principios de neutralidad e imparcialidad, advirtiendo a la persona mediadora de su obligación de «preservar su igualdad en la negociación» para que las partes alcancen por sí mismas soluciones al asunto sometido a mediación. En lo referente a las materias objeto de mediación, excede del ámbito familiar para dar cabida en un ámbito absolutamente integral con una visión general y omnicomprensiva. Se le otorga un carácter finalista a la mediación, en el sentido de que es labor de la persona mediadora que las partes alcancen por sí mismas soluciones (artículo 6.2).

Respecto a las materias excluidas de la mediación se encuentran aquellas que no sean de libre disposición, así como cualquier asunto en el que exista violencia o maltrato (art. 5.4). A esto añade a continuación que «se excluyen de la mediación los supuestos en que, a juicio del mediador o profesional competente, las partes no se encuentre en un plano de igualdad». A modo de insistencia en este planteamiento, en su artículo 28.3 especifica que «la persona mediadora puede dar por acabada la mediación en el momento que aprecie en alguna de las partes falta de voluntad o desigualdad de poder entre las misma...». Analizados estos preceptos deja claro el límite de intervención tanto en situaciones de violencia como en cualquier situación de desigualdad de poder a criterio de quien dirige el proceso de mediación. Por tanto, si bien esta ley ha supuesto avance en cuanto a la extensión del ámbito de intervención, se ha atribuido un límite que pudiera ser aplicado de forma extensiva a una variedad de situaciones de conflicto, resultando incapacitante.

En la Comunidad de Aragón, se ha aprobado la Ley 9/20II, de 24 de marzo, de mediación familiar para regular el procedimiento de resolución extrajudicial de los conflictos que se plantean en el ámbito familiar. Aún siendo éste el comienzo de su preámbulo, avanza el texto legal ampliando la mediación al ámbito extra e intrajudicial y dotando al proceso de un carácter resolutivo y también preventivo. Este aspecto tiene un carácter significativo, en tanto se refiere a las situaciones familiares de malos tratos. Es decir, atribuye a la mediación la característica de favorecer el diálogo, el acercamiento y la comprensión, para llegar a soluciones pactadas, así como «evitando y previniendo en muchas ocasiones situaciones familiares de malos tratos». 
Sin embargo, no resulta coherente si se le adjudica a la mediación un carácter preventivo en la escalada de la violencia familiar, que se establezca a su vez en el preámbulo la «prohibición expresa de acudir a mediación familiar cuando se está incurso en determinados procesos penales o cuando se advierta de la existencia de indicios de violencia doméstica o de género». A esto se añade el principio de igualdad (artículo 7 b) que considera que «ambas partes tienen los mismos derechos y obligaciones en el desarrollo del proceso», con lo cual sería contradictorio con la limitación mencionada. Con relación a los principios de imparcialidad y neutralidad los nombra en varias ocasiones a lo largo del texto (preámbulo, artículos 7. e), 7. f), Io d), llegando a precisar que se deben garantizar de forma absoluta, constituyendo su incumplimiento una infracción muy grave (artículo 28 e)).

En definitiva, ambas leyes autonómicas siendo las últimas aprobadas en el 20II, con posibilidad de ser innovadoras, se han reafirmado en los principios tradicionales de la mediación, llegando incluso a definirlos de forma más estricta y limitante para la intervención en gestión de conflictos en situaciones asimétricas.

Por último, mención especial corresponde a las comunidades de Aragón y Navarra por la asociación que han atribuido a la mediación con el concepto jurídico de la custodia compartida. Respectivamente en la Ley $2 / 20$ Io, de 26 de mayo de Cortes de Aragón, de igualdad en las relaciones familiares ante la ruptura de la convivencia de los padres y la Ley Foral de Navarra 3/20II, de I7 de marzo, sobre custodia de los hijos e hijas en los casos de ruptura de la convivencia de los padres, plasman estos dos conceptos en su regulación de la custodia compartida con el propósito de promover este modelo de organización familiar y, a su vez, derivar a la mediación aquellos conflictos en los cuales este aspecto haya motivado el inicio de un procedimiento judicial. El enfoque de este estudio nos lleva a plantear el riesgo que genera la asociación de conceptos como la custodia compartida y la mediación, ya que implica combinar un concepto jurídico como resultado de un proceso de gestión de conflictos basado en la autodeterminación de las partes, con lo cual es altamente probable que genere distorsión tanto del proceso como de la pretensión al menos de una de las partes que acude a mediación.

\section{Conclusiones. Aspectos comunes sobre la viabilidad de la mediación: límites y cuestionamientos éticos}

A modo de cierre de este capítulo de revisión y análisis de contenido de la normativa europea, estatal y autonómica, se especifican los aspectos observados y los cuestionamientos éticos en la medida que son relevantes para el objeto de estudio. La preocupación que ha acompañado el análisis legislativo ha sido la búsqueda de respuestas cuando existe desequilibrio de poder o cualquier conducta que genere situaciones de asimetría entre las partes que protagonizan una mediación, tomando de referencia los principios y aspectos deontológicos propuestos por el movimiento profesional de la resolución de conflictos (Alzate y Merino 20I0).

En primer lugar, si bien la R (98) i se viene identificando como el marco de referencia de los principios inspiradores de la mediación, esta norma no cierra la puerta, $a$ priori y de modo absoluto, a los supuestos de violencia, sino que parece remitir al caso concreto para determinar su conveniencia o no. Paradójicamente, cuando esta Recomendación ha sido trasladada al ámbito estatal y autonómico, ha sido interpretado de modo estricto en cuanto a considerar la violencia un concepto único y limitador de la intervención en mediación. Es decir, si bien la Recomendación europea citaba la expresión «supuestos de violencia», sin considerarlos inmediatamente un límite absoluto a la mediación, sí lo han considerado la legislación estatal y las autonómicas. 
En esta Recomendación se identificaban el principio de imparcialidad como una actitud ante las partes y la neutralidad con referencia al acuerdo, sin dar mayor detalle de aplicación práctica. Ambos principios se han ido plasmando en las sucesivas leyes autonómicas y, llamativamente, no han sido reflejados en la última Directiva 2008/52/CE. Algo novedoso de esta Directiva que será traspuesta en la legislación española a lo largo del 20 II (salvo incumplimiento de plazo), es que en las definiciones de mediación y persona mediadora se omite el concepto de neutralidad. Se mantiene la expresión de cómo se llevará a cabo la mediación «de forma ágil, imparcial y competente», dando a entender que interesa tanto la brevedad del proceso como su calidad. De hecho, se pone especial atención en la formación de aquellas personas que vayan a actuar como mediadoras. En su artículo 4 hace referencia tanto a la necesidad de formación inicial como a la formación continua, recordando la importancia de la ética y los códigos de conducta.

Otra de las características a destacar es el concepto de mediación que aporta la Directiva, resaltando su autonomía respecto del procedimiento judicial. La relevancia de esta definición radica en su carácter extrajudicial, ejercida por una persona en un plano de igualdad con las partes, lo cual excluye en todos los casos al juez en la actividad profesional de la mediación.

Al analizar el Proyecto de Ley estatal, si bien su finalidad es trasponer la Directiva citada, con el objetivo de ofrecer garantías de profesionalidad y calidad, regula un estatuto mínimo de la persona mediadora, con las únicas condiciones de tener un seguro de responsabilidad civil y estar inscrito en un registro público y de información gratuita. Posteriormente, en el texto final del Proyecto, el foco de interés se ha derivado hacia el valor de los acuerdos como cosa juzgada, posiblemente de ahí surja el requisito de contar con un seguro de responsabilidad civil, habiéndose olvidado de cualquier exigencia de formación inicial o continua. Por tanto, escasa concordancia ofrece el proyecto final con la necesidad de formación previa y continua que refiere la Directiva 2008/52/CE que es la que se traspone.

Respecto a la legislación civil estatal, es la que ha permitido la aplicabilidad de la mediación en el ámbito familiar. En los últimos años, desde la aprobación de la Ley 15/2005 de modificación del Código Civil y la Ley de Enjuiciamiento Civil, se ha generado un amplio y diverso campo de actuación para la actividad profesional en mediación familiar. Si bien, tal como se ha detallado previamente, las leyes relacionadas con Derecho de Familia han ampliado las posibilidades de actuación, ha sido la Ley de medidas de Protección Integral contra la Violencia de Género la que ha reducido y limitado la intervención. En esta Ley, por un lado, se pretende intervenir desde diferentes perspectivas jurídicas, incluso con carácter preventivo y educativo y, sin embargo, por otro lado, anula cualquier abordaje desde la mediación.

En el ámbito autonómico, se observa que todas las leyes de mediación, de algún modo, directo o indirecto, limitan la intervención en casos de violencia. En concreto, las leyes previas a la aprobación de la ley de violencia no la mencionan como límite de la intervención en mediación, sin embargo, sí lo hacen de forma precisa las que se han aprobado con posterioridad a la Ley Orgánica I/2004, de 28 de diciembre, de Medidas de Protección Integral contra la Violencia de Género.

Por tanto, ante el reconocimiento amplio de la mediación en el ámbito civil y la limitación rotunda en el ámbito de la violencia, se hace necesaria la reformulación de la pregunta. Es decir, quizá ya no se trate de preguntar si se puede mediar en conflictos familiares donde hay expresión de violencia sino la cuestión iría encaminada a encontrar el tipo de intervención que pueda garantizar que las partes reduzcan la escalada de la violencia, les permita interrumpir la dinámica violenta en la que estaban, incluso que lleguen a acuerdos. En la medida que la respuesta sea cercana a procesos de gestión de conflictos, se permitiría incluir los procesos de mediación con carácter flexible y respetando 
las necesidades concretas de las partes protagonistas, incluso con medidas de protección durante el propio proceso, si fueran precisas, con el objetivo de garantizar el interés de las partes.

En este sentido, voces expertas en la intervención y en la investigación en mediación familiar, discrepan abiertamente, en relación a la prohibición genérica que ha impuesto el legislador, proponiendo generar procesos que den respuesta a las necesidades de las partes (Alzate, Merino y Méndez, 20II). Pues dado que es admitido que la violencia de género puede ser graduada en diferentes niveles, se debería regular esta materia de una manera más flexible y abierta, permitiendo que en cada caso concreto se adopte la mejor medida posible. En esta línea de argumentación, se entiende y se defiende que se pudiera intervenir en supuestos de violencia leve o puntual, a través de procesos de mediación combinados con otras intervenciones, bien de carácter psicológico, pedagógico o psicosocial.

Ante la diversidad de regulaciones autonómicas, en aras del principio de igualdad, tal como refiere Lasheras (2009), para que todas las personas tengan las mismas posibilidades de acudir a mediación cuando se vean inmersas en un conflicto, resulta necesaria en cumplimiento de la D.F. $3^{\text {a }}$ de la Ley I5/2005 y de la Directiva 2008/52/CE, la pronta regulación de la mediación familiar. Esta institucionalización de la mediación mediante una ley nacional, debería quedarse en una norma de mínimos que permita el desarrollo adaptativo de la mediación a las necesidades sociales de cada momento y contexto. Tal como expresa Bernal (2005), el riesgo de la regulación es que suponga restar protagonismo a las características distintivas de la mediación. Si bien, esta regulación mínima sería deseable que hiciera referencia a la formación de quien ejerza este tipo de procesos, así como ampliar las posibilidades de intervención a situaciones de asimetría, incluso valorar la posibilidad de intervenir en relaciones con episodios de violencia de baja intensidad. 
Fuente: Merino (20II). Tesis doctoral. Tabla I7: Análisis de contenido: Legislación autonómica en mediación familiar y regulación de principios.

\begin{tabular}{|c|c|c|c|c|c|}
\hline Ley & Neutralidad & Imparcialidad & Inmediatez & Flexibilidad & Violencia \\
\hline $\begin{array}{l}\text { Ley } 4 / 200 \text { I } \\
\text { Galicia }\end{array}$ & Art. 8 & Art. 8.2 & Art. 8.I & $\begin{array}{c}\text { Art. } 8 \\
\text { Antiformalismo }\end{array}$ & No especifica \\
\hline Ley 7/200I Valencia & Art. 9f) & Art. 9g) & Art. 8 & $\begin{array}{l}\text { Art. } 8 \text { y } 9 \\
\text { Libertad }\end{array}$ & No especifica \\
\hline $\begin{array}{l}\text { Ley I5/2003 } \\
\text { Canarias }\end{array}$ & Art. $4 \cdot 5^{\circ}$ & Art. $4.5^{\circ}$ & Art. $4 \cdot 3$ & Art. 4.2 & No especifca \\
\hline $\begin{array}{c}\text { Ley } 4 / 2005 \text { Castilla } \\
\text { la Mancha }\end{array}$ & Art. 8 & Art. 8 & Art. I9 & $\begin{array}{c}\text { Art. } 8 \\
\text { Profesionalidad }\end{array}$ & Art. I7 \\
\hline $\begin{array}{c}\text { Ley I/2006 Castilla } \\
\text { y León }\end{array}$ & Art. 8.5 & Art. 8.5 & $\begin{array}{l}\text { Art. } 4.8 \text { No } \\
\text { represnte. }\end{array}$ & $\begin{array}{l}\text { Celeridad y } \\
\text { sencillez }\end{array}$ & Art. $4 \cdot 5$ \\
\hline $\begin{array}{l}\text { Ley I4/20io } \\
\text { Illes Balears }\end{array}$ & Art. 2c) & Art. 2d) & Art. 2f) & Art. 2g) & Art. 4.4 \\
\hline Ley I/2007 Madrid & Art. 4c) & Art. 4c) & Art. 4e) & Art. 4e) & Art. 8.2. \\
\hline Ley $3 / 2007$ Asturias & $\begin{array}{l}\text { Art. } 5 \text { Velar } \\
\text { equilib. }\end{array}$ & Art. 6 & Art. 8 & Preámbulo & $\begin{array}{c}\text { Disp. } \\
\text { Adicional }\end{array}$ \\
\hline $\begin{array}{l}\text { Ley i } / 2008 \\
\text { País Vasco }\end{array}$ & Art. 8f) & Art. 8e) & Art. 8i) & Art. 8g) & Art. 5.4 \\
\hline $\begin{array}{l}\text { Ley I/2009 } \\
\text { Andalucía }\end{array}$ & Art. 8.2 & Art. 8.I & Art.Io & Art. I2 & Art. 2.I \\
\hline $\begin{array}{l}\text { Ley I5/2009 } \\
\text { Cataluña }\end{array}$ & Art. 6.I/ 6.2 & Art. 6.I / 6.2 & Art.8.I /8.2 & $\begin{array}{l}\text { Regula } \\
\text { procedmto. }\end{array}$ & $\begin{array}{c}\text { Art. } \mathrm{I}_{6 . \mathrm{I}} \mathrm{b} / \mathrm{Art} \text {. } \\
\text { G. }\end{array}$ \\
\hline $\begin{array}{l}\text { Ley I/20II } \\
\text { Cantabria }\end{array}$ & Art. 6. & Art. 6 & Art I2 & Art. Iо & $\begin{array}{l}\text { Art. } 5.4 \text { / } \\
\text { Art.5.5 }\end{array}$ \\
\hline Ley 9/20II Aragón & Art. 7f) / 9d) & Art. 7e) ( Iod) & $\begin{array}{l}\text { Art. } 7 \text { h) No } \\
\text { represnte. }\end{array}$ & Art. 7g) & Preámbulo \\
\hline
\end{tabular}

Tabla I7. Tesis doctoral de Merino C., 20II 


\section{Bibliografía}

ALZATE, R., MERINO, C. (20I0): «Principios éticos y Código de Conducta para personas y entidades mediadoras», DOXA. Cuadernos de Filosofía del Derecho 33.

ALZATE, R. MERINO, C. y MÉNDEZ. M. (2OII): «Generando opciones en mediación», en Soleto, H. (dir.), Mediación y Solución de conflictos: Técnicas y ámbitos, Madrid: Ed. Tecnos.

BERNAL, T. (I993): «Primer Programa Público de Mediación Familiar: Resultados I993», Anuario de Psicología Jurídica 3, p. 43-54.

CAlAMANDREI, P. (1962): Estudios Sobre el Proceso Civil, Buenos Aires: Ediciones Jurídicas Europa-América.

DE SALAS, S. (I993): «Junta de parientes y la mediación familiar». Ponencia presentada en Jornadas La mediación, una cuestión de sociología jurídica. Instituto Internacional de Sociología Jurídica. Universidad de Oñate.

GARCÍA VILLALUENGA, L. (2005): La mediación familiar en el Derecho de Familia español. Especial referencia a la adopción. Tesis doctoral. Universidad Complutense de Madrid.

LÓPEZ, R. y LÓPEZ, J. (2003): Legislación sobre mediación familiar, Madrid: Ed. Tecnos.

LASHERAS, P. (2009): «Notas para una Ley nacional de mediación familiar intrajudicial», Simposio sobre Tribunales y Mediación. Nuevos caminos para la Justicia. Comunicaciones.

MERINO, C. (20I0): «Gestión de conflictos familiares desde un servicio público de mediación familiar I9962009", en García Villaluenga, L., Tomillo, J. y Vázquez de Castro, E. (coords.), Mediación, Arbitraje y Resolución extrajudicial de conflictos en el siglo XXI. Tomo I Mediación. Madrid: Ed. Reus.

MERINO, C. (2OII): «La mediación familiar en situaciones asimétricas. Estudio de la imparcialidad y neutralidad de la persona mediadora a partir de la intervención profesional en un servicio público de mediación familiar». Tesis doctoral Universidad del País Vasco, UPV/EHU.

MORCILlO, J. (20I0): «Marco jurídico del Derecho de Familia y de la Mediación familiar». Trabajo de Doctorado, sin publicar. UNED.

RISKIN, L. (2003): «Decision Making in Mediation: The New Old Grid ante The New Grid system», Notre Dame Law Review 79 (I), p. I-53. 